\title{
The use of helical tomotherapy in the treatment of early stage breast cancer: indications, tolerance, efficacy-a single center experience
}

\author{
Alexandre Arsene-Henry ${ }^{1}$, Jean-Philippe Foy ${ }^{2}$, Magalie Robilliard ${ }^{1}$, Hao-Ping $\mathrm{Xu}^{1,3}$, \\ Louis Bazire ${ }^{1}$, Dominique Peurien ${ }^{1}$, Philip Poortmans ${ }^{1}$, Alain Fourquet ${ }^{1}$ and Youlia \\ M. Kirova ${ }^{1}$ \\ ${ }^{1}$ Department of Radiation Oncology, Institut Curie, Paris, France \\ ${ }^{2}$ University Claude Bernard Lyon 1, INSERM 1052, CNRS 5286, Cancer Research Center of Lyon, Lyon, France \\ ${ }^{3}$ Department of Radiation Oncology, Ruijin Hospital, Shanghai, China \\ Correspondence to: Youlia M. Kirova, email: youlia.kirova@curie.fr \\ Keywords: helical tomotherapy; early stage breast cancer; indications; tolerance; efficacy \\ Received: January 24, $2018 \quad$ Accepted: March 12, $2018 \quad$ Published: May 04, 2018 \\ Copyright: Arsene-Henry et al. This is an open-access article distributed under the terms of the Creative Commons Attribution License 3.0 (CC \\ BY 3.0), which permits unrestricted use, distribution, and reproduction in any medium, provided the original author and source are credited.
}

\section{ABSTRACT}

Purpose: to evaluate our experience in terms of local control, survival, adverse effects in patients treated by adjuvant helical tomotherapy (HT) for breast cancer (BC).

Results: We studied 179 consecutive patients with 194 treated breasts with adjuvant HT. Median follow-up was $\mathbf{3 8 . 1}$ months. Median age was 53 years. Chemotherapy was administered to $83 \%$ of patients. All 133 hormone receptor positive tumours received hormonal therapy. As concurrent treatment, apart from trastuzumab monotherapy, 6 patients received systemic therapy concomitant to RT. The HT was generally well tolerated with mostly grade 1 and 2 skin reactions and esophagitis. Only 3\% grade III early skin reactions. At last follow-up, there were 2 local recurrences, 1 regional lymph node (LN) recurrence and 6 with metastatic progression. The 5-year progression-free survival was $90.5 \%$ (95\% CI 84.2-97.3).

Materials and Methods: A retrospective study of all patients treated by HT between 2009 and 2015 was done. Patients excluded were those with: breast implants, advanced or metastatic BC, recurrent disease. All patients received breast+/-boost or chest wall irradiation and most received with LN irradiation. Dose constraints for organs at risk were defined using optimization scale developed in our Department. Evaluation of early and late toxicity was done using Common Terminology Adverse Criteria Events v.4.0.

Conclusions: HT can be used for a well selected group of breast cancer as bilateral tumours, complex anatomy and target volumes where the conventional radiation therapy techniques cannot ensure an optimal dose distribution. Longer follow-up is necessary to confirm and validate these results.

\section{INTRODUCTION}

Breast cancer is the most common malignant tumour in women worldwide [1]. Postoperative radiation therapy (RT) is part of standard treatment after surgery, either mastectomy or breast- conserving surgery. In particular, postoperative RT improves local control and disease-free survival and decreases mortality [2, 3]. A meta-analysis of several randomized trials demonstrated the benefit of internal mammary (IM), supraclavicular and infraclavicular lymph node irradiation in patients with axillary lymph node invasion or at high risk of recurrence [4].

However, RT can induce early and late adverse effects, including cosmetic sequelae and impaired quality of life [5]. It can also induce pulmonary and cardiac toxicity $[6,7]$. Conventional breast or chest wall RT is based on two opposing tangential beams, resulting in high 
dose heterogeneity [8]. More recently, various techniques to optimize dose homogeneity, including intensitymodulated RT (IMRT), have been shown to be superior in terms of target volume coverage, and organ-at-risk (OAR) sparing [8-11]. This dosimetric optimization allows a reduction of RT-related adverse effects [12-15], while local control and survival appear to be similar $[13,16]$.

Rotational IMRT has been developed more recently, in the form of helical tomotherapy (HT) or volumetricmodulated arc therapy (VMAT). Dosimetric studies have shown that these techniques improve the target volume coverage and dose distribution homogeneity and can decrease the high dose to OAR, especially in the context of irradiation of complex volumes [17-21].

The purpose of this study was to evaluate local control, survival and adverse effects in patients treated by HT for non-metastatic breast cancer.

\section{RESULTS}

Between 2009 and 2015, a total of 274 patients were treated for breast cancer by HT. Ninety-five patients were excluded from the study: 59 patients with metastatic disease, 9 patients with locally advanced tumour, 15 patients with breast prosthesis, 10 patients treated for recurrent disease and 2 patients with regional lymph node involvement with no known primary. Finally, 179 patients treated by postoperative HT for non-metastatic breast cancer were included in our study. Fifteen of these patients had a bilateral cancer, resulting in a total of 194 treated breasts.

\section{Patients and tumours characteristics (Table 1)}

Median follow-up was 38.1 months (range: 7.4-78.2). The median age of the patients was 53 years (range: $25-76$ years), of them only 25 patients $(14 \%)$ were younger than 40 . The characteristics of the patients included in the study are presented in Table 1A. The majority of patients received RT to one breast $(n=140)$, and 24 patients received chest wall RT. Right and left sides were treated with equal frequency. Fifty-three patients had a history of at least one cardiovascular disease and 18 patients had a history of lung disease.

Tumours were nonspecific invasive carcinomas in $85 \%$ of cases, 5 patients had carcinoma in situ, $47 \%$ of tumours were grade 3 , about one-half of patients had no clinical lymph node involvement and 33 patients had triple-negative tumours. Tumours characteristics are presented in Table 1B.

\section{Surgery}

All patients were operated on, by breast-conserving surgery in $84 \%$ of cases and by mastectomy in the remaining cases. Axillary lymph node surgery consisted of immediate axillary lymph node dissection in $45 \%$ of cases, sentinel node procedure in $30 \%$ of cases and axillary lymph node dissection following a positive sentinel node in $23 \%$ of cases. No axillary lymph node surgery was performed in 3 patients.

\section{Systemic therapy}

Chemotherapy was administered to $83 \%$ of patients, in the adjuvant setting in $61 \%$ of patients and in the primary setting in $39 \%$ of patients. Most patients (91\%) received an anthracycline-based chemotherapy protocol followed by a taxane. Four of the 25 patients with an HER+ tumour did not receive trastuzumab. Almost three-quarters of the population $(n=133)$ received hormonal therapy for HR+ tumours. As concurrent treatment, apart from trastuzumab monotherapy, 6 patients received systemic therapy concomitant to RT, including FUN chemotherapy (5FU + vinorelbine) in 4 cases.

\section{Radiation therapy}

Eighty-five per cent of patients received lymph node irradiation combined with breast or chest wall irradiation. Level II, III, IV and IM lymph nodes were irradiated in $57 \%$ of these patients; level IV and IM in $11 \%$ and all regional lymph nodes in $16 \%$. No lymph node irradiation was performed in $15 \%$ of patients.

One hundred fifty-two patients $(78 \%)$ received a boost dose to the tumour bed. In $83 \%$ of cases, the boost dose was delivered according to the simultaneous integrated boost (SIB) technique. Concomitant chemotherapy, mainly $5 \mathrm{FU}+$ vinorelbine, was administered in $3 \%$ of the cases.

The median duration of treatment was 46 days.

\section{Outcome (Figure 1)}

At last follow-up, there were 2 cases of local recurrence $(1 \%), 1$ case of regional lymph node recurrence and 6 cases of metastatic progression. The later consisted of 3 cases of lung metastases, 2 cases of bone metastases, 2 cases of liver metastases, 1 case of cerebromeningeal metastases and 1 case of choroidal metastases. Some patients presented with disease progression in multiple sites.

Three patients had died at the end of follow-up: 2 from breast cancer and one from metastatic malignant melanoma.

The 5-year progression-free survival (PFS) was $90.5 \%$ (95\% CI 84.2-97.3) (Figure 1A). PFS by molecular subgroup was $83.4 \%$ (95\% CI 69.6-99.9), $85.7 \%$ (95\% CI $63.3-100)$ and $92.9 \%$ (95\% CI $86-$ $100)$ for triple- negative (TN), HER+ and HR+/HER2subgroups, respectively $(p=0.13)$ (Figure 1B). 
Table 1: Patients' and tumour characteristics

\begin{tabular}{|c|c|c|}
\hline Characteristics & $n$ & $\%$ \\
\hline Median age (range) & $53(25-76)$ & \\
\hline Median BMI (range) & $24.9(16.3-53.4)$ & \\
\hline \multicolumn{3}{|l|}{ Tobacco } \\
\hline No & 148 & 83 \\
\hline Yes & 27 & 15 \\
\hline Unknown & 4 & 2 \\
\hline \multicolumn{3}{|l|}{ Breast cup size } \\
\hline A & 10 & 5 \\
\hline $\mathrm{B}$ & 48 & 25 \\
\hline $\mathrm{C}$ & 51 & 26 \\
\hline$\geq \mathrm{D}$ & 44 & 23 \\
\hline Unknown & 41 & 21 \\
\hline \multicolumn{3}{|l|}{ Localisation } \\
\hline Right breast & 72 & 40 \\
\hline Left breast & 68 & 38 \\
\hline Left chest wall & 12 & 7 \\
\hline Right chest wall & 12 & 7 \\
\hline Bilateral & 15 & 8 \\
\hline \multicolumn{3}{|l|}{ History of CV disease } \\
\hline AHT & 28 & 16 \\
\hline Dyslipidaemia & 25 & 14 \\
\hline Diabetes & 8 & 4 \\
\hline Phlebitis & 8 & 4 \\
\hline Arrhythmia & 2 & 1 \\
\hline Myocardial infarction & 1 & 1 \\
\hline Other & 5 & 3 \\
\hline \multicolumn{3}{|c|}{ History of pulmonary disease } \\
\hline Asthma & 14 & 8 \\
\hline Chronic bronchitis & 4 & 2 \\
\hline Other & 1 & 1 \\
\hline
\end{tabular}

Abbreviations: $\mathrm{BMI}=$ Body mass index; $\mathrm{AHT}=$ arterial hypertension $; \mathrm{CV}=$ cardiovascular.

Table 1B: Tumour characteristics $(n=194)$

\begin{tabular}{lcc}
\hline \multicolumn{1}{c}{ Characteristics } & $\boldsymbol{n}$ & \% \\
\hline Quadrant & & 43 \\
External & 83 & 40 \\
Internal & 77 & 15 \\
Central & 29 & 2 \\
Unknown & 5 & 85 \\
Histology & & 8
\end{tabular}


Carcinoma In situ

Mixed (Ductal and lobular) 5

Other

5

3

$3-2$

Clinical tumour stage

cT1 102

cT2

102

59

24

6

cT4

Unknown

Clinical nodal stage

cNO 93

$\mathrm{cN} 1$

$\mathrm{cN} 2$

cN3

Unknown

80

1

4

16

HER 2

Yes

Unknown

Triple negative

Yes

Unknown

HR+

Yes

No

Unknown

SBR grade

Low (I)
253

$$
2
$$

30

12

3

2

48

41

1

2

8

13

84

3

17

80

3

76

21

3

9

40

47

4

Abbreviations: HER $2=$ human epidermal growth factor receptor 2 ; HR $+=$ Hormone receptor positive; SBR $=$ ScarffBloom-Richardson.

Patients with initial clinically lymph node involvement $(\mathrm{cN}+)$ lymph node involvement with negative lymph node status after primary chemotherapy had a 5-year PFS of 94.4\% (95\% CI 84.4-100). Patients with persistent lymph node involvement after primary chemotherapy had a 5-year PFS of $78.2 \%$ (95\% CI $58.8-$ 100) $(p=0.25)$ (Figure 2).

Four patients developed a second cancer after treatment of their breast cancer. A contralateral carcinoma in situ was diagnosed in one patient 1.6 years after completion of RT. One patient developed a left sacroiliac sarcoma, one patient developed a neuroendocrine tumour of the duodenum and another patient developed papillary thyroid carcinoma 1.3 years after completion of RT to the right chest wall and lymph node areas.

\section{Early toxicity (Table 2A and 2B)}

Acute cutaneous toxicity consisted of radiationinduced dermatitis scored as grade 0 or 1 in $57 \%$ of patients, grade 2 in $40 \%$ of cases and grade 3 in $3 \%$ of cases. Gastrointestinal toxicity consisted of esophagitis in $18 \%$ of cases (16\% of grade 1 and $2 \%$ of grade 2, but no grade 3 ). All patients experiencing acute esophagitis were irradiated to level IV and IM 
lymph nodes. Two patients experienced dry cough that resolved spontaneously during RT. Decreased left ventricular ejection function (from $62 \%$ to $50 \%$ ) was observed during RT in 1 hypertensive patient, who had received anthracycline-based adjuvant chemotherapy in combination with trastuzumab prior to irradiation of the left breast with a boost dose and irradiation of the, level II, III, IV, IP and IM lymph nodes.

A high body mass index (BMI) $(p<0.0001)$ and a history of cardiovascular disease $(p=0.04)$, especially hypertension $(\mathrm{HT})(p=0.005)$, were associated with a significantly higher risk of acute cutaneous toxicity. Cup size and smoking did not significantly influence this risk. On multivariate analysis, only BMI was significantly associated with an increased risk of acute cutaneous toxicity. The results of these analyses are presented in Table 2A and 2B.

Of note, patients with high BMI $\left(>25 \mathrm{~kg} \cdot \mathrm{m}^{-2}\right)$ have a higher risk of acute skin toxicity (grade 0 or 1 versus grade 2 or more) compared to patients with $\mathrm{BMI}<25$ $\mathrm{kg} \cdot \mathrm{m}^{-2}$, in a multivariate analysis including age, HT and cup size $(\mathrm{OR}=4,1 ; 95 \%$ IC $1,97-8,83 ; p=0,0002)$.

None of the risk factors for acute cutaneous toxicity studied was significantly associated with an increased risk of acute gastrointestinal toxicity.

\section{Late toxicity (Table 2)}

Late toxicities are summarized in Table 2C. Late cutaneous toxicity was observed in $31 \%$ of patients. This toxicity was limited to grade 1 in the great majority of cases with hyperpigmentation in $9 \%$ of cases, fibrosis in $12 \%$ of cases, breast edema in $7 \%$ of cases, and telangiectasia in $6 \%$ of cases. Grade 2 late cutaneous toxicities were observed in 5\% of cases, with no cases of grade 3 toxicity. Six per cent of patients experienced persistent grade 1 breast pain. No late cardiac or pulmonary toxicity was observed.

Advanced age $(p=0.04)$, higher BMI $(p=0.004)$, and large cup size $(p=0.02)$ were significantly associated with an increased risk of late cutaneous toxicity. In contrast, neither a history of cardiovascular disease nor smoking was significantly associated with an increased risk of late cutaneous toxicity. On multivariate analysis, only BMI was significantly associated with an increased risk of late cutaneous toxicity. The results of these analyses are presented in Table 2A and $2 \mathrm{~B}$.

\section{OAR and target volumes}

Results concerning target volume coverage are previously reported [11]. HT ensures good coverage in the presence of complex volumes.

The results of dosimetric analysis in terms of OAR are presented in Table 3. In this study, the mean dose received by the heart, ipsilateral lung, contralateral lung and contralateral breast was 7 Gy, 13.5 Gy, 5 Gy and 3.8 Gy, respectively. The ipsilateral lung received a mean V30 equal to $9.6 \%$. In contrast, the contralateral lung and breast received low doses with a mean V5 equal to $32 \%$ and $16.3 \%$, respectively.

\section{DISCUSSION}

This largest with the longest follow-up study confirms that the HT is a well-tolerated treatment for breast cancer, with good local and distant disease control, especially in complex volumes (described
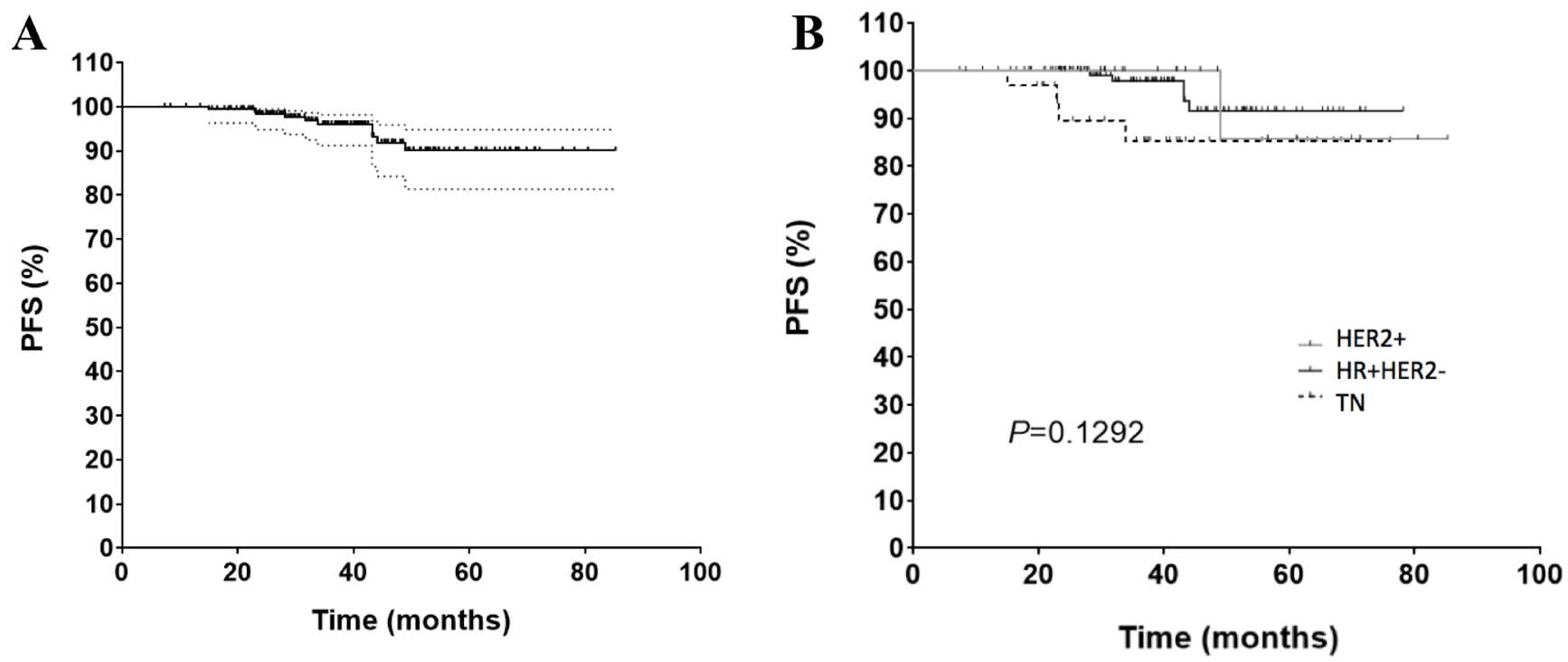

Figure 1: Progression-free survival (PFS) in (A) all the patients and (B) according to molecular profile. Abbreviations: PFS: Progression free survival; TN = triple negative; HER $2+=$ human epidermal growth factor receptor 2 overexpressed; HR $+=$ Hormone receptor positive. 
Table 2: Toxicity

\begin{tabular}{|c|c|c|c|c|c|c|}
\hline & \multicolumn{3}{|c|}{ Acute skin toxicity ${ }^{*}$} & \multicolumn{3}{|c|}{ Late skin toxicity $^{*}$} \\
\hline & No $(\%)$ & Yes $(\%)$ & $P$-value & No (\%) & Yes $(\%)$ & $P$-value \\
\hline \multicolumn{7}{|l|}{ Age } \\
\hline Median & 51 & 55 & 0.1987 & 51 & 56 & 0.039 \\
\hline$[\min ; \max ]$ & {$[25 ; 74]$} & {$[32 ; 76]$} & & {$[25 ; 74]$} & {$[32 ; 76]$} & \\
\hline \multicolumn{7}{|l|}{ BMI } \\
\hline Median & 23.5 & 27.3 & $<0.0001$ & 24.02 & 27.3 & 0.004 \\
\hline$[\min ; \max ]$ & {$[16.3 ; 53.4]$} & {$[17.7 ; 44.5]$} & & {$[16.3 ; 53.4]$} & {$[18.9 ; 51.3]$} & \\
\hline \multicolumn{7}{|l|}{ Tabaco use } \\
\hline Yes & $13(11.8)$ & $17(20.2)$ & 0.159 & $20(15.5)$ & $7(13.0)$ & 0.819 \\
\hline No & $94(85.5)$ & $65(77.4)$ & & $106(82.2)$ & $45(83.3)$ & \\
\hline Unknown & $3(2.7)$ & $2(2.4)$ & & $3(2.3)$ & $2(3.7)$ & \\
\hline \multicolumn{7}{|c|}{ Breast cup size } \\
\hline A-B-C & $72(65.5)$ & $49(58.3)$ & 0.1134 & $89(69.0)$ & $28(51.9)$ & 0.018 \\
\hline D-E-F-G & $20(18.2)$ & $25(29.8)$ & & 24 (18.6) & $19(35.2)$ & \\
\hline Unknown & $18(16.4)$ & $10(11.9)$ & & $16(12.4)$ & $7(13.0)$ & \\
\hline \multicolumn{7}{|l|}{$\begin{array}{l}\text { History of CV } \\
\text { disease }\end{array}$} \\
\hline Yes & $26(23.6)$ & $32(38.1)$ & 0.0397 & $38(29.5)$ & $18(33.3)$ & 0.725 \\
\hline No & $83(75.5)$ & $52(61.9)$ & & $90(69.8)$ & $36(66.7)$ & \\
\hline Unknown & $1(0.9)$ & $0(0.0)$ & & $1(0.8)$ & $0(0.0)$ & \\
\hline \multicolumn{7}{|l|}{ AHT } \\
\hline Yes & $10(9.1)$ & $21(25.0)$ & 0.005 & $19(14.7)$ & $11(20.4)$ & 0.385 \\
\hline No & $99(90.0)$ & $63(75.0)$ & & $109(84.5)$ & $43(79.6)$ & \\
\hline Unknown & $1(0.9)$ & $0(0.0)$ & & $1(0.8)$ & $0(0.0)$ & \\
\hline \multicolumn{7}{|l|}{ Diabetes } \\
\hline Yes & $4(3.6)$ & $5(6.0)$ & 0.5062 & $8(6.2)$ & $0(0.0)$ & 0.107 \\
\hline No & $105(95.5)$ & $79(94.0)$ & & $120(93.0)$ & $54(100.0)$ & \\
\hline Unknown & $1(0.9)$ & $0(0.0)$ & & $1(0.8)$ & $0(0.0)$ & \\
\hline \multicolumn{7}{|l|}{ Dyslipidaemia } \\
\hline Yes & $13(11.8)$ & $15(17.9)$ & 0.3036 & $18(14.0)$ & $10(18.5)$ & 0.514 \\
\hline No & $96(87.3)$ & $69(82.1)$ & & $110(85.3)$ & $44(81.5)$ & \\
\hline Unknown & $1(0.9)$ & $0(0.0)$ & & $1(0.8)$ & $0(0.0)$ & \\
\hline
\end{tabular}

"For acute skin toxicity: "No" included grade 0 and 1 ; for late skin toxicity: "No" included only grade 0.

Abbreviations: $\mathrm{BMI}=$ Body mass index; $\mathrm{AHT}=$ arterial hypertension; $\mathrm{CV}=$ cardiovascular.

Table 2B: Multivariate analysis of risk factors for acute and late skin toxicity

\begin{tabular}{|c|c|c|c|c|c|c|}
\hline & \multicolumn{3}{|c|}{ Acute skin toxicity } & \multicolumn{3}{|c|}{ Late skin toxicity } \\
\hline & OR & $95 \% \mathrm{CI}$ & $P$-value & OR & $95 \% \mathrm{CI}$ & $P$-value \\
\hline Age & 1.01 & [0.98-1.04] & 0.56 & 1.03 & [0.99-1.06] & 0.12 \\
\hline BMI & 1.07 & [1.01-1.15] & 0.04 & 1.07 & [1.00-1.14] & 0.048 \\
\hline Breast cup size ${ }^{*}$ & 1.24 & {$[0.55-2.74]$} & 0.6 & 1.81 & {$[0.81-4.03]$} & 0.14 \\
\hline AHT & 2.55 & {$[0.87-8.15]$} & 0.1 & NA & NA & NA \\
\hline
\end{tabular}


Table 2C: Late toxicities $(n=194)$

\begin{tabular}{lccc}
\hline Late toxicity & Yes (\%) & No (\%) & Unknown (\%) \\
\hline Pulmonary & $(0)$ & $(100)$ & $(0)$ \\
Cardiac & $(0)$ & $(100)$ & $(0)$ \\
Cutaneous & $60(31)$ & $130(67)$ & $4(2)$ \\
\hline & Grade 1 (\%) & Grade 2 (\%) & Grade 3 (\%) \\
\hline Hyperpigmentation & $18(9)$ & $1(1)$ & 0 \\
Breast oedema & $14(7)$ & $1(1)$ & 0 \\
Fibrosis & $24(12)$ & $3(2)$ & 0 \\
Telangiectasia & $4(6)$ & $2(1)$ & 0 \\
Breast pain & $11(6)$ & $1(1)$ & 0 \\
\hline
\end{tabular}

above) when RT cannot be delivered via conventional (3D-CRT) techniques. This series represents the first large homogeneous single center experience in the use of helical tomotherapy in terms of efficacy and toxicity, as well as the practical proposal of adapted doses to OAR in these particular situations (bilateral cancers in $15 \%$ of patients, $85 \%$ of lymph node irradiation, high number of pectus excavatum). These complex volumes explain the higher doses to heart in comparison with the general recommendations [6]. The main limitation of this study is its retrospective nature and the period of follow-up of 38.1 months, which can be explained by the fact that HT was initially used for other tumour sites, but, after a number of years of experience, its indications have now been extended [18, 22]. Low level of complications was observed in terms of lung and heart toxicity. Progressionfree survival in this study was very satisfactory, but these results must be interpreted cautiously in view of the relatively short median follow-up.

IMRT, especially helical HT, has been shown to improve target volume coverage, dose conformity, and dose homogeneity [8, 11, 19]. This dosimetric improvement can reduce acute and late toxicity $[14,23]$. However, these techniques raise the issue of low-dose irradiation of a larger volume of healthy tissues and its possible long-term impact, particularly in terms of radiation-induced cancer [24, 25], especially as breast cancer patients have a long mean life expectancy [26]. In order to decrease this risk, we decided not to treat women under the age of 40 .

Breast or chest wall irradiation by conventional techniques can lead to irradiation of a part of the heart and be associated with an increased risk of late cardiac toxicity depending on the mean dose to the heart [6]. Several approaches have been introduced to lower the radiation dose to the heart, including cardiac shielding, respiratory control and (volumetric) IMRT $[11,17,19]$. However, HT delivers low doses to a larger part of the heart, resulting in a higher mean dose. Longer follow-up of these patients is essential to evaluate the long-term impact of this low-dose irradiation. In the meantime, IMRT should be combined with respiratory control in selected patients [24]. HT allows a significant reduction of the dose received by the ipsilateral lung, but, due to its rotational nature, this technique induces low-dose irradiation of the contralateral lung, resulting in an increased mean dose received and V5\% [11, 17]. Another limitation to the use of the HT in breast cancer is the low-dose irradiation of the contralateral breast, to a much lower extent observed with conventional techniques [27], raising the possibility of radiation-induced secondary cancers [25, 27-29]. Stovall et al. showed that women under the age of 40 who received a dose greater than 1 Gy to the contralateral breast had an increased long-term risk of developing a second primary breast cancer [29]. This excess risk was not observed in women $>40$.

The simultaneous integrated boost (SIB) technique has already been applied to breast cancer RT [22, 30-32]. In combination with 3DCRT or IMRT, this technique improves dose conformity at the tumour bed, decreases the delivery of high doses and the dose to OAR compared to a sequential boost $[22,30-32]$. SIB induces a reduction of treatment time and increased doses per fraction to the tumour bed, which could theoretically increase local control [33].

\section{MATERIALS AND METHODS}

\section{Patients}

A retrospective study was conducted in the Department of Radiation Oncology. All patients treated by HT between 2009 and 2015 for non-metastatic breast cancers were included in the study. Patients presenting with the following criteria were excluded: breast implants, advanced and metastatic breast cancer, recurrences. Data were collected until March 2017.

HT was used in specific cases in which conventional techniques were unsatisfactory in terms of target volume coverage and dose to OAR, most commonly corresponding to patients with unusual anatomy (pectus excavatum, narrow intermammary cleft), large breast volume, deeply 
Table 3: Doses to organs at risk according to the irradiated area (Mean +/- SD)

\begin{tabular}{|c|c|c|c|c|c|c|c|c|c|}
\hline & \multirow{2}{*}{$\begin{array}{c}\text { Heart } \\
\text { Mean dose } \\
(\mathrm{Gy})\end{array}$} & \multicolumn{4}{|c|}{ Homolateral lung } & \multicolumn{2}{|c|}{ Controlateral lung } & \multicolumn{2}{|c|}{ Controlateral breast } \\
\hline & & $\begin{array}{l}\text { Mean dose } \\
\text { (Gy) }\end{array}$ & V20 (\%) & V30 (\%) & $\begin{array}{l}\text { Mean dose } \\
\text { (Gy) }\end{array}$ & V5 (\%) & V20 (\%) & $\begin{array}{l}\text { Mean dose } \\
\text { (Gy) }\end{array}$ & V5 (\%) \\
\hline Right breast & $6.8+/-1.3$ & $13.8+/-1.9$ & $20.8+/-5$ & $9.3+/-3.8$ & $4.4+/-1.3$ & $31.9+/-11.4$ & $0.5+/-2.4$ & $3.9+/-1.1$ & $16.3+/-11.1$ \\
\hline Left breast & $6.9+/-1.6$ & $13+/-2.3$ & $20.7+/-5.5$ & $9.5+/-3.2$ & $4.7+/-0.8$ & $36+/-11.1$ & $0.2+/-0.3$ & $3.9+/-0.8$ & $16.7+/-9.2$ \\
\hline $\begin{array}{l}\text { Right chest } \\
\text { wall }\end{array}$ & $6.8+/-1.0$ & $14+/-1.8$ & $23+/-4.9$ & $10.2+/-2.8$ & $4.0+/-0.5$ & $27.9+/-6.7$ & 0 & $3.6+/-0.6$ & $15.5+/-7.3$ \\
\hline $\begin{array}{l}\text { Left chest } \\
\text { wall }\end{array}$ & $7.8+/-1.1$ & $13.3+/-1.7$ & $20.3+/-4.8$ & $9.3+/-3.3$ & $6.8+/-6.6$ & $32.5+/-4.5$ & $0.4+/-0.5$ & $3.9+/-0.7$ & $16.6+/-9.0$ \\
\hline
\end{tabular}

Abbreviations: $\mathrm{SD}=$ Standard deviation; $\mathrm{Vx}=$ volume that received more than $\mathrm{xGy}$.

seated IM lymph nodes, medial tumours with associated IM irradiation, bilateral cancer with lymph node irradiation. A high proportion of the patients' population was referred by other radiotherapy departments because of the inability to treat the patients with conventional techniques and acceptable doses to OAR.

The following parameters were analyzed: patient and tumour characteristics, treatments received, early and late toxicities, local, regional and distant recurrences, and progression-free survival (PFS). PFS corresponds to the time between the end of RT and local, regional or distant disease progression. Patients had a clinical examination every week during radiation therapy and after, the followup consisted of every 4 months clinics in patients who received chemotherapy and every 6 months till the 5th year after the treatment, then once per year.

\section{Surgery}

First-line breast-conserving treatment was performed whenever possible. Some patients received primary systemic treatment. Mastectomy was performed when breastconserving surgery was not possible. Breast surgery included lymph node dissection in $\mathrm{N}+$ patients, and sentinel lymph node biopsy in N-neg. patients, completed by axillary lymph node dissection in the case of positive sentinel node.

\section{Systemic therapy}

The majority of patients received chemotherapy, mostly anthracycline-based chemotherapy followed by taxanes. When the tumour overexpressed the Human Epidermal Growth Factor-2 (HER-2) receptor, patients

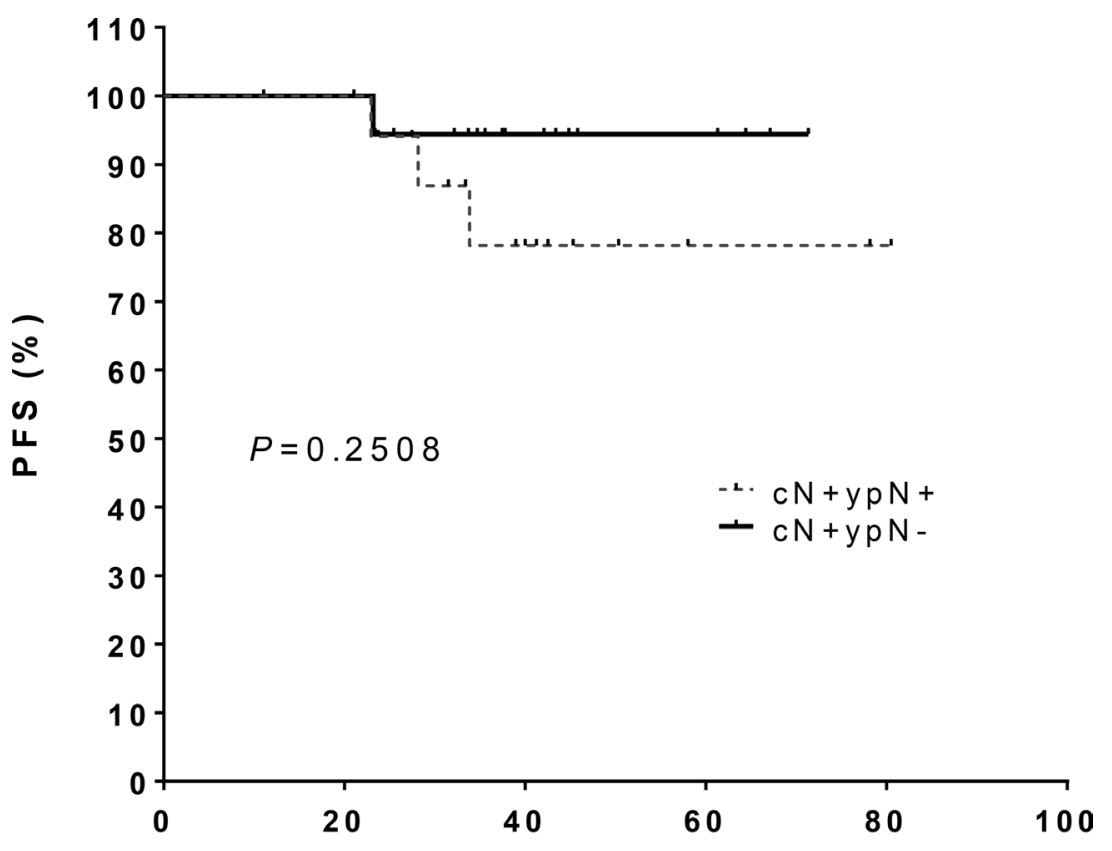

Time (months)

Figure 2: Progression-free survival in patients with initial clinically lymph node involvement $(\mathrm{cN}+)$ who received primary chemotherapy and who either had a complete remission lymph node status (ypN-) or maintained lymph node involvement (ypN+). 
received trastuzumab for one year. Patients with tumours expressing hormone receptors received hormonal therapy for 5 years adapted to their menopausal status: Tamoxifen for premenopausal women and an aromatase inhibitor for postmenopausal women.

\section{Treatment planning CT scan}

A CT scan (3 mm slices) was performed from the Tragus to L2/L3 without contrast agent using a Toshiba Aquilion LB scanner (Toshiba). Patients were placed in supine position with an AIO positioning system (ORFIT, Wijnegem Belgium) on a $5^{\circ}$ inclined plane. An immobilization device was placed under the patient's knees. Both arms were positioned above the patient's head. A chin rest integrated in a heat-formed mask limited repositioning errors. Both breasts and the surgical scars were marked with radiopaque markers.

\section{Target volumes delineation}

CT sections were transferred to the contouring system (Eclipse 3D version 13.6; Varian Medical Systems Inc., Palo Alto, USA). The breast/chest wall and lymph node clinical target volumes (CTV) were delineated according to our guidelines then ESTRO guidelines after the official publication [34]. The primary tumour bed was contoured according to previously described methods [35]. A $5 \mathrm{~mm}$ expansion around the CTV was performed to define the planning target volume (PTV). The PTV was cropped $3 \mathrm{~mm}$ under the skin.

\section{Prescription}

The prescribed dose was 50 Gy in 25 fractions (2 Gy/fraction) to the breast/chest wall and lymph nodes. When a breast with boost was indicated, it was delivered either sequentially at a dose of 16 Gy in 8 fractions or, in the majority of cases, by a simultaneous integrated boost technique, which delivered 52.2 Gy in 29 fractions (1.8 $\mathrm{Gy} /$ fraction) to the breast and $63.8 \mathrm{~Gy}$ (2.2 Gy/fraction) to the tumour bed. The dose was restricted then to $50.4 \mathrm{~Gy}$ (1.74 Gy/fraction) to the lymph node areas. The objective was the homogenous cover of $95 \%$ of the PTV by $>95 \%$ isodose.

\section{Organs at risk: optimization of dosimetry and dose constraints}

Fifty consecutive HT treatment plans to the breast or chest wall with lymph node irradiation, were used to calculate dose-volume histogram (DVH) values for each OAR (heart, ipsilateral lung, contralateral lung, contralateral breast and bone marrow). These dose values were classified in increasing order and divided into 4 classes (quartiles). Four quartiles of dose values were defined for each organ. $Q 1$ represents the maximum dose in the first quartile. Only $25 \%$ of treatment plans of the sample therefore presented a dose to the organ at risk of less than or equal to the $Q 1$ value. $Q 2$ represents the value of the median dose of the sample. $Q 3$ represents the maximum dose in the third quartile. Only $25 \%$ of treatment plans presented a higher dose than the $Q 3$ value. Q4 represents the maximum dose of the sample (Table 4).

For all new treatment plans, the lower than $Q 2$ dose constraint is now applied to each organ-at-risk in order to obtain optimal and sufficient intensity modulation of the beam to comply with clinical constraints. These dose constraints were developed in our Department with aim to decrease the doses to OAR in patients with complex anatomy and/or volumes of irradiation.

\section{Helical tomotherapy treatment planning}

CT scan and contoured volumes were transferred to the HT planning station (TomoTherapy HI-ART version 3.1.2.3; TomoTherapy Inc., Madison, United States). All treatment plans were calculated with a pitch of 0.286 , a modulation factor initially set at 2.5 and a collimation of $2.5 \mathrm{~cm}$.

Two fictitious volumes were created in the treatment planning system to limit the low doses delivered to healthy tissues. No irradiation was allowed when the accelerator passed over the contralateral hemi body or the patient's posterior surface.

\section{Patients' follow-up and evaluation of toxicities}

Patients were examined weekly during RT, then 4 to 6 months after the end of RT and then every 6 months, alternately by the medical oncologist (in the case of chemotherapy), surgeon/gynaecologist and radiation oncologist. Acute cutaneous, gastrointestinal, pulmonary and cardiac toxicities were evaluated retrospectively using Common Terminology Adverse Criteria Events v.4.0 [36].

Late toxicities were evaluated on the most recent consultation report and at least 6 months after completion of RT.

\section{Statistical methods}

Statistical analysis was performed with $\mathrm{R}$ programming language and GraphPad Prism software version 6.00, (GraphPad software, Inc., San Diego, CA). The distributions of quantitative and qualitative variables were expressed by the mean and standard deviation (quantitative variables), or as a percentage (qualitative variables). Statistical analysis of qualitative variables was performed by Fisher's exact test. Mann-Whitney's nonparametric test was used to compare each continuous quantitative variable between the two groups. The association between clinical factors and gastrointestinal and cutaneous toxicity was tested 
Table 4: Dose to organs at risk treated with helical tomotherapy

\begin{tabular}{|c|c|c|c|c|c|c|}
\hline \multicolumn{7}{|c|}{ Heart } \\
\hline & Dmean (Gy) & Dmed (Gy) & V5 (\%) & V10 (\%) & V25 (\%) & \\
\hline Q1 & $<6.4$ & $<5$ & $<48$ & $<17$ & $<0$ & \\
\hline Q2 & $<7.1$ & $<6$ & $<57$ & $<20$ & $<2$ & \\
\hline Q3 & $<8.5$ & $<7$ & $<69$ & $<25$ & $<3$ & \\
\hline Q4 & $<10.3$ & $<8$ & $<83$ & $<35$ & $<6$ & \\
\hline \multicolumn{7}{|c|}{ Ipsilateral lung } \\
\hline & Dmean (Gy) & Dmed (Gy) & V5 (\%) & V20 (\%) & V30 (\%) & \\
\hline Q1 & $<11.9$ & $<7.7$ & $<67$ & $<17$ & $<7$ & \\
\hline Q2 & $<13$ & $<9.2$ & $<75$ & $<20$ & $<9$ & \\
\hline Q3 & $<14.6$ & $<10.6$ & $<88$ & $<23$ & $<13$ & \\
\hline Q4 & $<18$ & $<14.4$ & $<100$ & $<33$ & $<17$ & \\
\hline \multicolumn{7}{|c|}{ Contralateral breast } \\
\hline & Dmean (Gy) & Dmed (Gy) & V3 (\%) & V5 (\%) & V7 (\%) & V10 (\%) \\
\hline Q1 & $<3.3$ & $<2.8$ & $<44$ & $<8$ & $<2.3$ & $<0$ \\
\hline Q2 & $<3.6$ & $<3.2$ & $<59$ & $<14$ & $<3.3$ & $<0$ \\
\hline Q3 & $<3.9$ & $<3.3$ & $<64$ & $<17$ & $<6.2$ & $<1$ \\
\hline Q4 & $<5.7$ & $<4.3$ & $<89$ & $<37$ & $<19.7$ & $<9$ \\
\hline \multicolumn{7}{|c|}{ Contralateral lung } \\
\hline & Dmean (Gy) & Dmed (Gy) & V5 (\%) & V7 (\%) & V10 (\%) & \\
\hline Q1 & $<4$ & $<3.6$ & $<29$ & $<9$ & $<1$ & \\
\hline Q2 & $<4.5$ & $<4.1$ & $<35$ & $<12$ & $<2$ & \\
\hline Q3 & $<4.8$ & $<4.5$ & $<40$ & $<16$ & $<4$ & \\
\hline Q4 & $<6.6$ & $<5.9$ & $<69$ & $<32$ & $<12$ & \\
\hline \multicolumn{7}{|c|}{ Spinal cord } \\
\hline & Dmean (Gy) & Dmed (Gy) & $\mathrm{D} \max (\mathrm{Gy})$ & & & \\
\hline Q1 & $<5.6$ & $<3.1$ & $<23$ & & & \\
\hline Q2 & $<7.3$ & $<5$ & $<28$ & & & \\
\hline Q3 & $<8.8$ & $<6.5$ & $<34$ & & & \\
\hline Q4 & $<11.9$ & $<10.6$ & $<42$ & & & \\
\hline
\end{tabular}

Abbreviations: $\mathrm{Q}=$ quartile; Dmean $=$ mean dose $;$ Dmed $=$ median dose; Dmax $=$ maximum dose $; \mathrm{Vx}=$ volume that received more than $\mathrm{xGy}$.

on multivariate analysis using a logistic regression model. Specific progression-free survival (PFS) was defined as the interval between the end of RT and the date of the first disease-related event (local, regional or distant recurrence and cancer-related death). Survival curves were plotted by the Kaplan-Meier method and were compared by a logrank test. A $p$ value $<0.05$ was considered to be statistically significant.

\section{CONCLUSIONS}

HT can be used for a well selected group of breast cancer such as bilateral tumours, complex anatomy and target volumes where the conventional techniques cannot ensure an optimal dose distribution with good efficacy and tolerance. Longer follow-up is necessary to confirm and validate these results.

\section{CONFLICTS OF INTEREST}

The authors declare that they have no conflicts of interest.

\section{FUNDING}

Access fees were sponsored by Accuray ${ }^{\circledR}$. 


\section{REFERENCES}

1. Ghoncheh M, Pournamdar Z, Salehiniya H. Incidence and Mortality and Epidemiology of Breast Cancer in the World. Asian Pac J Cancer Prev. 2016; 17:43-46. https:// doi.org/10.7314/APJCP.2016.17.S3.43.

2. McGale P, Taylor C, Correa C, Cutter D, Duane F, Ewertz M, Gray R, Mannu G, Peto R, Whelan T, Wang Y, Wang Z, Darby S, and EBCTCG (Early Breast Cancer Trialists' Collaborative Group). Effect of radiotherapy after mastectomy and axillary surgery on 10-year recurrence and 20-year breast cancer mortality: meta-analysis of individual patient data for 8135 women in 22 randomised trials. Lancet. 2014; 383:2127-35. https://doi.org/10.1016/ S0140-6736(14)60488-8.

3. Darby S, McGale P, Correa C, Taylor C, Arriagada R, Clarke M, Cutter D, Davies C, Ewertz M, Godwin J, Gray R, Pierce L, Whelan T, et al, and Early Breast Cancer Trialists' Collaborative Group (EBCTCG). Effect of radiotherapy after breast-conserving surgery on 10-year recurrence and 15-year breast cancer death: meta-analysis of individual patient data for 10,801 women in 17 randomised trials. Lancet. 2011; 378:1707-16. https://doi.org/10.1016/S01406736(11)61629-2.

4. Budach W, Bölke E, Kammers K, Gerber PA, NestleKrämling C, Matuschek C. Adjuvant radiation therapy of regional lymph nodes in breast cancer - a meta-analysis of randomized trials- an update. Radiat Oncol. 2015; 10:258. https://doi.org/10.1186/s13014-015-0568-4.

5. Hille-Betz U, Vaske B, Bremer M, Soergel P, Kundu S, Klapdor R, Hillemanns P, Henkenberens C. Late radiation side effects, cosmetic outcomes and pain in breast cancer patients after breast-conserving surgery and threedimensional conformal radiotherapy: risk-modifying factors. Strahlenther Onkol. 2016; 192:8-16. https://doi. org/10.1007/s00066-015-0899-y.

6. Darby SC, Ewertz M, McGale P, Bennet AM, BlomGoldman U, Brønnum D, Correa C, Cutter D, Gagliardi G, Gigante B, Jensen MB, Nisbet A, Peto R, et al. Risk of ischemic heart disease in women after radiotherapy for breast cancer. N Engl J Med. 2013; 368:987-98. https://doi. org/10.1056/NEJMoa1209825.

7. Chargari C, Kirov KM, Bollet MA, Magné N, Védrine L, Cremades S, Beuzeboc P, Fourquet A, Kirova YM. Cardiac toxicity in breast cancer patients: from a fractional point of view to a global assessment. Cancer Treat Rev. 2011; 37:321-30. https://doi.org/10.1016/j.ctrv.2010.08.007.

8. Barnett GC, Wilkinson J, Moody AM, Wilson CB, Sharma R, Klager S, Hoole AC, Twyman N, Burnet NG, Coles CE. A randomised controlled trial of forward-planned radiotherapy (IMRT) for early breast cancer: baseline characteristics and dosimetry results. Radiother Oncol. 2009; 92:34-41. https:/ doi.org/10.1016/j.radonc.2009.03.003.

9. Richmond ND, Turner RN, Dawes PJ, Lambert GD, Lawrence GP. Evaluation of the dosimetric consequences of adding a single asymmetric or MLC shaped field to a tangential breast radiotherapy technique. Radiother Oncol. 2003; 67:165-70. https://doi.org/10.1016/S01678140(03)00008-2.

10. Donovan EM, Bleackley NJ, Evans PM, Reise SF, Yarnold JR. Dose-position and dose-volume histogram analysis of standard wedged and intensity modulated treatments in breast radiotherapy. Br J Radiol. 2002; 75:967-73. https:// doi.org/10.1259/bjr.75.900.750967.

11. Lauche O, Kirova YM, Fenoglietto P, Costa E, Lemanski C, Bourgier C, Riou O, Tiberi D, Campana F, Fourquet A, Azria D. Helical tomotherapy and volumetric modulated arc therapy: new therapeutic arms in the breast cancer radiotherapy. World J Radiol. 2016; 8:735-42. https://doi. org/10.4329/wjr.v8.i8.735.

12. Donovan E, Bleakley N, Denholm E, Evans P, Gothard L, Hanson J, Peckitt C, Reise S, Ross G, Sharp G, SymondsTayler R, Tait D, Yarnold J, and Breast Technology Group. Randomised trial of standard 2D radiotherapy (RT) versus intensity modulated radiotherapy (IMRT) in patients prescribed breast radiotherapy. Radiother Oncol. 2007; 82:254-64. https://doi.org/10.1016/j.radonc.2006.12.008.

13. Mukesh MB, Barnett GC, Wilkinson JS, Moody AM, Wilson C, Dorling L, Chan Wah Hak C, Qian W, Twyman N, Burnet NG, Wishart GC, Coles CE. Randomized controlled trial of intensity-modulated radiotherapy for early breast cancer: 5-year results confirm superior overall cosmesis. J Clin Oncol. 2013; 31:4488-95. https://doi. org/10.1200/JCO.2013.49.7842.

14. Pignol JP, Olivotto I, Rakovitch E, Gardner S, Sixel K, Beckham W, Vu TT, Truong P, Ackerman I, Paszat L. A multicenter randomized trial of breast intensity-modulated radiation therapy to reduce acute radiation dermatitis. J Clin Oncol. 2008; 26:2085-92. https://doi.org/10.1200/ JCO.2007.15.2488.

15. Buwenge M, Cammelli S, Ammendolia I, Tolento G, Zamagni A, Arcelli A, Macchia G, Deodato F, Cilla S, Morganti AG. Intensity modulated radiation therapy for breast cancer: current perspectives. Breast Cancer (Dove Med Press). 2017; 9:12126. https://doi.org/10.2147/BCTT.S113025.

16. Keller LM, Sopka DM, Li T, Klayton T, Li J, Anderson PR, Bleicher RJ, Sigurdson ER, Freedman GM. Fiveyear results of whole breast intensity modulated radiation therapy for the treatment of early stage breast cancer: the Fox Chase Cancer Center experience. Int J Radiat Oncol Biol Phys. 2012; 84:881-87. https://doi.org/10.1016/j. ijrobp.2012.01.069.

17. Caudrelier JM, Morgan SC, Montgomery L, Lacelle M, Nyiri B, Macpherson M. Helical tomotherapy for locoregional irradiation including the internal mammary chain in left-sided breast cancer: dosimetric evaluation. Radiother Oncol. 2009; 90:99-105. https://doi. org/10.1016/j.radonc.2008.09.028.

18. Chira C, Kirova YM, Liem X, Campana F, Peurien D, Amessis M, Fournier-Bidoz N, Pierga JY, Dendale R, Bey 
P, Fourquet A. Helical tomotherapy for inoperable breast cancer: a new promising tool. Biomed Res Int. 2013; 2013:264306. https://doi.org/10.1155/2013/264306.

19. Goddu SM, Chaudhari S, Mamalui-Hunter M, Pechenaya OL, Pratt D, Mutic S, Zoberi I, Jeswani S, Powell SN, Low DA. Helical tomotherapy planning for left-sided breast cancer patients with positive lymph nodes: comparison to conventional multiport breast technique. Int J Radiat Oncol Biol Phys. 2009; 73:1243-51. https://doi.org/10.1016/j. ijrobp.2008.11.004.

20. Lauche O, Kirova YM. Helical tomotherapy in breast cancer treatment. Breast Cancer Manag. 2014; 3:441-49. https:// doi.org/10.2217/bmt.14.34.

21. Popescu CC, Olivotto IA, Beckham WA, Ansbacher W, Zavgorodni S, Shaffer R, Wai ES, Otto K. Volumetric modulated arc therapy improves dosimetry and reduces treatment time compared to conventional intensitymodulated radiotherapy for locoregional radiotherapy of left-sided breast cancer and internal mammary nodes. Int J Radiat Oncol Biol Phys. 2010; 76:287-95. https://doi. org/10.1016/j.ijrobp.2009.05.038.

22. Hijal T, Fournier-Bidoz N, Castro-Pena P, Kirova YM, Zefkili S, Bollet MA, Dendale R, Campana F, Fourquet A. Simultaneous integrated boost in breast conserving treatment of breast cancer: a dosimetric comparison of helical tomotherapy and three-dimensional conformal radiotherapy. Radiother Oncol. 2010; 94:300-06. https:// doi.org/10.1016/j.radonc.2009.12.043.

23. Yang JF, Lee MS, Lin CS, Chao HL, Chen CM, Lo CH, Fan CY, Tsao CC, Huang WY. Long-Term Breast Cancer Patient Outcomes After Adjuvant Radiotherapy Using IntensityModulated Radiotherapy or Conventional Tangential Radiotherapy. Medicine (Baltimore). 2016; 95:e3113. https://doi.org/10.1097/MD.0000000000003113.

24. Osman SO, Hol S, Poortmans PM, Essers M. Volumetric modulated arc therapy and breath-hold in image-guided locoregional left-sided breast irradiation. Radiother Oncol. 2014; 112:17-22. https://doi.org/10.1016/j. radonc.2014.04.004.

25. Kirova YM, Gambotti L, De Rycke Y, Vilcoq JR, Asselain B, Fourquet A. Risk of second malignancies after adjuvant radiotherapy for breast cancer: a large-scale, singleinstitution review. Int J Radiat Oncol Biol Phys. 2007; 68:359-63. https://doi.org/10.1016/j.ijrobp.2006.12.011.

26. INCA_Cancer_Survie_Sein.pdf. [Cited 2017 Aug 22]. Available from: http://www.e-cancer.fr/Professionnels-desante/Les-chiffres-du-cancer-en-France/Epidemiologie-descancers/Les-cancers-les-plus-frequents/Cancer-du-sein.

27. Bazire L, De Rycke Y, Asselain B, Fourquet A, Kirova YM. Risks of second malignancies after breast cancer treatment: long-term results. Cancer Radiother. 2017; 21:10-15. https://doi.org/10.1016/j.canrad.2016.07.101.
28. Boice JD Jr, Harvey EB, Blettner M, Stovall M, Flannery JT. Cancer in the contralateral breast after radiotherapy for breast cancer. N Engl J Med. 1992; 326:781-85. https://doi. org/10.1056/NEJM199203193261201.

29. Stovall M, Smith SA, Langholz BM, Boice JD Jr, Shore RE, Andersson M, Buchholz TA, Capanu M, Bernstein L, Lynch CF, Malone KE, Anton-Culver H, Haile RW, et al, and Women's Environmental, Cancer, and Radiation Epidemiology Study Collaborative Group. Dose to the contralateral breast from radiotherapy and risk of second primary breast cancer in the WECARE study. Int J Radiat Oncol Biol Phys. 2008; 72:1021-30. https://doi. org/10.1016/j.ijrobp.2008.02.040.

30. Hurkmans CW, Meijer GJ, van Vliet-Vroegindeweij C, van der Sangen MJ, Cassee J. High-dose simultaneously integrated breast boost using intensity-modulated radiotherapy and inverse optimization. Int J Radiat Oncol Biol Phys. 2006; 66:923-30. https://doi.org/10.1016/j. ijrobp.2006.05.041.

31. Singla R, King S, Albuquerque K, Creech S, Dogan N. Simultaneous-integrated boost intensity-modulated radiation therapy (SIB-IMRT) in the treatment of earlystage left-sided breast carcinoma. Med Dosim. 2006; 31:190-96. https://doi.org/10.1016/j.meddos.2005.11.001.

32. van der Laan HP, Dolsma WV, Maduro JH, Korevaar EW, Hollander M, Langendijk JA. Three-dimensional conformal simultaneously integrated boost technique for breast-conserving radiotherapy. Int $\mathrm{J}$ Radiat Oncol Biol Phys. 2007; 68:1018-23. https://doi.org/10.1016/j. ijrobp.2007.01.037.

33. Qi XS, White J, Li XA. Is $\alpha / \beta$ for breast cancer really low? Radiother Oncol. 2011; 100:282-88. https://doi. org/10.1016/j.radonc.2011.01.010.

34. Offersen BV, Boersma LJ, Kirkove C, Hol S, Aznar MC, Biete Sola A, Kirova YM, Pignol JP, Remouchamps V, Verhoeven K, Weltens C, Arenas M, Gabrys D, et al. ESTRO consensus guideline on target volume delineation for elective radiation therapy of early stage breast cancer. Radiother Oncol. 2015; 114:3-10. https://doi.org/10.1016/j. radonc.2014.11.030.

35. Kirova YM, Castro Pena P, Hijal T, Fournier-Bidoz N, Laki F, Sigal-Zafrani B, Dendale R, Bollet MA, Campana F, Fourquet A. Improving the definition of tumor bed boost with the use of surgical clips and image registration in breast cancer patients. Int J Radiat Oncol Biol Phys. 2010; 78:1352-55. https://doi.org/10.1016/j.ijrobp.2009.10.049.

36. CTCAE_4.03_2010-06-14_QuickReference_8.5x11. pdf. [cited 2017 Aug 22]. Available from: https://www. eortc.be/services/doc/ctc/CTCAE_4.03_2010-06-14_ QuickReference_5x7.pdf. 